\title{
Marketed as Unapproved Vitamin Product
}

National Cancer Institute

\section{Source}

National Cancer Institute. Marketed as Unapproved Vitamin Product. NCI Thesaurus.

Code $C 73615$.

A category specifying that a product is marketed as unapproved vitamin product. 